\title{
Modulating the Surface Properties of Metallic Implants and the Response of Breast Cancer Cells by Surface Relief Induced via Bulk Plastic Deformation
}

\author{
Benay Uzer* \\ Department of Mechanical Engineering, Abdullah Gül University, Kayseri, Turkey
}

Micro/nanoscale textured surfaces have presented promising tissue-implant integration via increasing surface roughness, energy, and wettability. Recent studies indicate that surface texture imparted on the metallic implants via surface relief induced with simple bulk plastic deformation methods (e.g., tension or compression tests) does result in enhanced cell response. Considering these recent findings, this study presents a thorough investigation of the effects of surface relief on surface properties of implants and cell adhesion. Experiments are conducted on the samples subjected to interrupted

OPEN ACCESS

Edited by:

Laura Maria Vergani,

Politecnico di Milano, Italy

Reviewed by:

Agata Przekora,

Medical University of Lublin, Poland

Jindan Wu,

Zhejiang Sci-Tech University, China

${ }^{*}$ Correspondence:

Benay Uzer

benay.uzer@agu.edu.tr

Specialty section

This article was submitted to

Biomaterials,

a section of the journal

Frontiers in Materials

Received: 06 January 2020

Accepted: 31 March 2020

Published: 07 May 2020

Citation:

Uzer B (2020) Modulating

the Surface Properties of Metallic

Implants and the Response of Breast

Cancer Cells by Surface Relief

Induced via Bulk Plastic Deformation.

Front. Mater. 7:99.

doi: 10.3389/fmats.2020.00099 tensile tests up to the plastic strains of $5,15,25$, and $35 \%$. Main findings from these experiments suggest that, as the plastic deformation level increases up to 35\% from the undeformed (control) level, (1) average surface roughness $\left(R_{\mathrm{a}}\right)$ increases from 17.58 to $595.29 \mathrm{~nm}$; (2) water contact angle decreases from 84.28 to $58.07^{\circ}$; (3) surface free energy (SFE) increases from 36.06 to $48.89 \mathrm{~mJ} / \mathrm{m}^{2}$; and (4) breast cancer cells show 2.4-fold increased number of attachment. Increased surface roughness indicates the distorted topography via surface relief and leads to increased wettability, consistent with Wenzel's theory. The higher levels of SFE observed were related to high-energy regions provided via activation of strengthening mechanisms, which increased in volume fraction concomitant with plastic deformation. Eventually, the displayed improvements in surface properties have increased the number of breast cancer cell attachments. These findings indicate that surface relief induced upon plastic deformation processes could be utilized in the design of implants for therapeutic or diagnostic purposes through capturing breast cancer cells on the material surface.

Keywords: plastic deformation, surface relief, metallic implants, breast cancer cells, adhesion, wettability, surface free energy, roughness

\section{INTRODUCTION}

Metallic materials constitute approximately $70 \%$ of the total production volume in biomedical applications (Peron et al., 2017), which stems from a set of excellent properties, such as mechanical strength, ductility, biocompatibility, and corrosion resistance (Chen and Thouas, 2015; Uzer et al., 2016; Peron et al., 2017; Nune et al., 2018). Austenitic stainless steels, titanium alloys, and cobaltchromium alloys can be listed among the most commonly used metallic biomaterials, which could 
find application in a wide variety of biomedical fields including cardiovascular surgery, orthopedics, dentistry, or cranioplasty (Misra et al., 2009; Chen and Thouas, 2015; Uzer et al., 2016; Nune et al., 2018).

Clinical success of the implantation strongly relies on early tissue-implant integration along with the elimination of fibrous connective tissue formation on the interface (Le Guéhennec et al., 2007; Hanawa, 2019). This integration can be influenced strongly by the implant surface wettability, which is indeed governed by surface free energy (SFE) and roughness of the material (Liu and Jiang, 2011; Latifi et al., 2013). Modification of these aforementioned surface properties can be utilized to trigger specific molecular reactions controlling the adhesion, proliferation, or differentiation behavior of the cells (Ventre et al., 2012; Barthes et al., 2014; Huo et al., 2017; Raines et al., 2019). For instance, microscale textured surfaces can regulate the expression of integrin, which is a transmembrane receptor protein enabling cell adhesion on the metal surface (Raines et al., 2019), or hydrophilic surfaces (contact angle $<90^{\circ}$ ) can promote enhanced cell response via promoting the deposition of focal adhesion proteins (Ponsonnet et al., 2003; Ranella et al., 2010; Bauer et al., 2013; Rupp et al., 2014; Cicek et al., 2019). Surface properties obviously play a crucial role in cell adhesion, and in order to reveal their cumulative effects, more thorough analyses are required.

Research carried out on the relationship between the surface properties and tissue-implant interaction has shown that mimicking the tissue microenvironment on the material surface via micro/nanoscale patterns can stimulate cell adhesion significantly (Le Guéhennec et al., 2007; Gentile et al., 2010; Barthes et al., 2014; Gui et al., 2018; Raines et al., 2019). These textured materials can provide increased mechanical stability and rigid tissue formation on the implant, which can lead to an earlier recovery after implantation (Kunrath and Hübler, 2019). Various surface treatment techniques have been utilized to create micro/nanoscale topography on the surface, such as acid etching, electrochemical polishing, passivation, or anodization (Le Guéhennec et al., 2007; Gentile et al., 2010; Latifi et al., 2013). These physical or chemical treatments have created textured structures, which have stimulated cell growth via providing greater surface area for the formation of focal adhesion points (Uzer et al., 2016). Moreover, increased roughness through these treatments has led to enhanced surface wettability, catalyzing the deposition of extracellular matrix (ECM) proteins on the surface (Miyajima et al., 2019).

Similar results were also obtained via surface mechanical treatments such as shot peening, sliding friction, or surface mechanical attrition treatment (SMAT) (Multigner et al., 2010; Arifvianto et al., 2011; Bagherifard et al., 2016; Valiev et al., 2016; Huo et al., 2017). Activation of these deformation mechanisms subdividing coarse grains into smaller sizes provided grain refinement in the near surface layer of the material (Arifvianto et al., 2011). Furthermore, these methods improved the fatigue resistance of the materials via inducing compressive residual stress on the surface (Arifvianto et al., 2011; Bagherifard et al., 2016). However, all of the aforementioned physical, chemical, or mechanical treatment methods were confined to the surface layer of the material.

Research has shown that micro/nanoscale topography mimicking morphology of ECM could also be utilized to control the response of cancer cells (Beri et al., 2018). For instance, Beri et al. (2018) found that circulating tumor cells' (CTCs') adhesion can be promoted on biomaterials with nanoscale roughness. It should be noted that metastasis accounts for approximately $90 \%$ of cancer-related diseases (Conde et al., 2016), and CTCs are believed to play crucial role in metastatic processes (Chen et al., 2016). Thus, use of surface roughness to enhance cancer cellsubstrate interactions would enable the capturing of CTCs and therefore decrease disease dissemination (Beri et al., 2018; Chen et al., 2016). Moreover, directional adhesion of breast cancer cells, which is necessitated for cancer invasion and metastasis, has been achieved by micro/nanoscale-patterned topography (Ray et al., 2017; Tabdanov et al., 2018). Overall, these studies can indicate that biomaterials with modulated topography could be promising tools for detection and treatment of cancer cells via controlling their adhesion response.

Recently, simple bulk plastic deformation methods (e.g., tension or compression tests) have been utilized to impart micro/nanoscale topography on the metal surface (Matsugaki et al., 2012; Matsugaki and Nakano, 2016; Uzer et al., 2016, 2018; Nune et al., 2018). These studies showed that texture reflecting the activated strengthening mechanisms, namely, surface relief, can alter surface topography significantly (Matsugaki et al., 2012; Matsugaki and Nakano, 2016; Uzer et al., 2016; Cicek et al., 2019). Specifically, markings produced by twinning or slip are shown to form groove- or step-like surface topographical features that can increase surface roughness and provide ideal sites for the deposition of focal adhesion proteins (Matsugaki et al., 2012; Uzer et al., 2016, 2018; Uzer and Canadinc, 2018).

Surface relief can be induced on the implant surface via manufacturing processes or during the deployment of the implants (Weiss and Mitevski, 2015). Furthermore, it can enable the oriented elongation of the osteoblast cells, which promotes the formation of anisotropic bone tissue necessary for its mechanical function (Matsugaki et al., 2012; Matsugaki and Nakano, 2016). Consequently, these microstructural features can increase cell viability and adhesion, which enhances tissue formation on the implant surface (Uzer et al., 2018). Moreover, they could be used to increase the adhesion of cancer cells (Uzer et al., 2016). It is noteworthy that the level of plastic strain constitutes importance, because excessive plastic deformation is accommodated through the activation of strengthening mechanisms in greater volume fractions within the bulk material. As a result, each deformation level results with a different surface state, causing healthy or cancer cell response to vary along each plastic strain level (Matsugaki et al., 2012; Uzer et al., 2016, 2018).

The aforementioned studies regarding plastic deformation of bulk materials have established a firm relationship between surface relief, roughness, and cell response. However, current state of knowledge in this area falls short of elucidating the relative change in surface wettability and energy, which are also strongly modulated via surface topography (Rupp et al., 2014). Given the established influence of these properties on cell 
response, this study aims to investigate the role of surface relief on surface wettability, energy, roughness, and cell attachment behavior. The findings propose the idea that surface relief could be an effective means to control surface properties and cell response. This knowledge could enable the design of metallic biomaterials that could be used for therapeutic purposes in dealing with cancer cells.

\section{MATERIALS AND METHODS}

The specimens investigated in the current study were $304 \mathrm{~L}$ grade stainless steels with the elemental composition of Fe balance-0.029C-18.414Cr-8.314Ni-1.044Mn-0.091Mo-0.369Si0.022P-0.023S-0.416Cu (in weight\%). Dog bone-shaped tensile test specimens with the technical drawing explained elsewhere (Cicek et al., 2019) were obtained by laser cutting. These samples were subjected to interrupted tensile tests (AGS-X 10kN; Shimadzu, Kyoto, Japan) up to the engineering strains of 5, 15, 25 , and $35 \%$ with the strain rate of $10^{-4} \mathrm{~s}^{-1}$. These varying strain values enabled the activation of strengthening mechanisms in different volume fractions throughout the bulk material, which also helped to have materials with different microstructural and surface properties. Moreover, one set of the samples was kept as undeformed in order to use as a control group.

After plastic deformation the gauge sections of the samples were cut with a precision saw. Microstructure of the undeformed and deformed specimens was captured via differential interference contrast (DIC) technique in optical microscope (Axiocam 506 color; Zeiss, Jena, Germany). For that purpose, the undeformed sample was ground with 800, 1,000, 1,200, and 2,500 grit SiC papers and then polished with 3 - and $1-\mu \mathrm{m}$ sized diamond abrasives, respectively. In order to reveal its microstructure, this polished specimen was then etched by immersing in a mixture of $10 \mathrm{~mL}$ nitric acid, $30 \mathrm{~mL}$ hydrochloric acid, and $30 \mathrm{~mL}$ distilled water for $3 \mathrm{~min}$ long at room temperature. The deformed sample's microstructure has been captured via extended depth of field imaging technique. The microstructures of the samples were also analyzed in detail via field emission scanning electron microscope (GeminiSEM 300; Zeiss, Jena, Germany) utilizing secondary electron (SE) detector, which operated at accelerating voltage of $10 \mathrm{kV}$.

In order to elucidate the effect of surface relief on the topography of the deformed and undeformed samples, atomic force microscopy was utilized (Multimode 8, Bruker). The analyses were carried out with tapping mode in air utilizing a phosphorus-doped silicon cantilever with a rotated tip (radius of $8 \mathrm{~nm}$ ), and linear scanning rate was of $1 \mathrm{~Hz}$ (1 line/s). Average surface roughness $\left(R_{\mathrm{a}}\right)$ of the samples was calculated by taking the average of the roughness values of at least three different regions with the scanning area of $50 \times 50 \mu \mathrm{m}$.

Wettability and SFE of the undeformed and deformed samples were analyzed with sessile drop technique (Attension Theta Optical Tensiometer; Biolin Scientific, Gothenburg, Sweden). Prior to the analyses, the samples were ultrasonically cleaned with acetone and 70\% vol/vol ethanol for $15 \mathrm{~min}$ and then dried in air. For the wettability analysis, deionized (DI) water droplet with the volume of $2 \mu \mathrm{L}$ was dispensed on the surface, and its shape was recorded with a high-speed camera. The final contact angle was reported as the average of the right and left angle, which is between the tangent of the drop at liquid-gas interface and horizontal baseline at solid-liquid interface. The analyses were run on three different samples for each strain level, and measurements were repeated five times on each one. For the SFE analyses, diiodomethane was used as the dispersive component; formamide and DI water were utilized as the polar components. Similar to the wettability measurements, the samples were cleaned with the same procedure before conducting measurements with different liquids. The measurements were repeated three times on each sample (three samples for each strain level). Recorded contact angle values of the three liquids were implemented in the Owens-Wendt (OW) theoretical method as (Miyajima et al., 2019):

$$
\gamma_{l}(1+\cos \theta)=2 \sqrt{\gamma_{s}^{d} \gamma_{l}^{d}}+2 \sqrt{\gamma_{s}^{p} \gamma_{l}^{p}}
$$

where $\gamma_{l}$ and $\gamma_{s}$ represent liquid and solid free energy; superscripts $d$ and $p$ represents the dispersive and polar components, respectively (Rupp et al., 2014).

In order to evaluate the effect of surface relief on cell response, breast cancer cells were seeded on the undeformed control sample and the 35\% deformed sample (highest degree of plastic deformation). Initially, SKBR3 breast cancer cells obtained from the American Type Culture Collection were grown in McCoy's 5A medium with $10 \%$ fetal bovine serum and $1 \%$ penicillin/streptomycin. Then, three samples from each set were sterilized in an autoclave for $1 \mathrm{~h}$ and placed in 12-well cell culture plate. Cancer cells were seeded in each well $\left(1 \times 10^{5}\right.$ cells per well) containing $2 \mathrm{~mL}$ of growth medium and then incubated for $24 \mathrm{~h}$. Afterward, the medium was removed, and the samples were rinsed with phosphate-buffered saline (PBS). The cells were fixed with $2.5 \%$ glutaraldehyde for $2 \mathrm{~h}$ at $37^{\circ} \mathrm{C}$, followed by rinsing with PBS. After this, the nuclei of these fixed cells were labeled with DAPI and incubated for $5 \mathrm{~min}$ at ambient temperature. Then the samples were rinsed again with PBS, and the cell adhesion was observed with confocal microscope through capturing three different images from each sample surface (LSM 900; Zeiss). The number of attached cells was quantified manually, and their average value was reported.

The morphology and adhesion behavior of cells were further analyzed via SEM under an accelerating voltage of $2 \mathrm{kV}$ with the SE detector. In order to enhance the quality of the SEM images, the metallic samples were cleaned with DI water to remove the residues of the PBS and sputtered with a 2-nm thickness of gold to eliminate the charging problem. To the best of the author's knowledge, the adhesion response of the breast tumor cells has not been analyzed on a metallic biomaterial surface earlier. Hence, this study can pave the way for future research regarding the relationship between breast cancer cells and metallic biomaterials.

All of the reported results are presented as mean \pm standard deviation. Statistical significance of the differences between the means was determined with one-way analysis of variance (ANOVA) followed by least-squares difference (LSD) post hoc 
comparison tests or $t$ tests. The findings were also supported by non-parametric equivalents of the aforementioned tests. A $p$ value smaller than 0.05 was required for the rejection of null hypotheses (highest type I error level deemed acceptable was set at 0.05).

\section{RESULTS}

The optical microscope image of the undeformed sample in Figure 1A presents smooth surface with annealing twins, where a detailed image of one of these twins can be observed in Figure 2A captured via SEM. As the sample is plastically strained, deformation markings become prevalent, and surface gets distorted significantly (Figure 1B). These activated deformation traces have been presented more clearly in Figure 2B. The interaction of these mechanisms (i.e., mechanical twinning, slip, or martensite) with each other can be also observed. Microstructures of the samples have been further analyzed via AFM (Figure 3). The effect of plastic deformation can be visible specifically on the $35 \%$ deformed sample, where significant grain elongation concomitant with plastic straining was captured (Figure 4).

The detailed AFM images present the topographies of the samples in Figure 3, where they get distorted gradually in parallel with plastic straining. Furthermore, increasing height between the peaks and valleys can be observed as the plastic deformation increases. Moreover, grain boundaries protruding out of the surface becomes prevalent on the 15, 25 , and 35\% samples (Figure 3). In order to quantitatively analyze the influence of plastic deformation on the surface topography, average surface roughness $\left(R_{\mathrm{a}}\right)$ of the samples is evaluated. The results present that $R_{\mathrm{a}}$ values of the samples vary from $17.58 \pm 1.12 \mathrm{~nm}$ in the undeformed sample to $595.29 \pm 32.74 \mathrm{~nm}$ in the $35 \%$ deformed sample (Table 1). One-way ANOVA results of the roughness data indicate that all group means are not equal $\left[F_{(4,18)}=459.16\right.$, $p<0.001]$. Additional post hoc multiple comparisons (LSD) indicate that all group means are significantly different from each other at $p<0.05$ level or better. These results are also confirmed by non-parametric Kruskal-Wallis tests $\left[\chi^{2}(4)=20.91 ; p<0.001\right]$.

The wettability measurements carried out by the DI water droplets on the samples subjected to the varying degrees of plastic deformation are presented in Table 1. The angle on the undeformed sample is captured as $84.28^{\circ} \pm 3.02^{\circ}$, whereas it decreases down to $58.07^{\circ} \pm 1.67^{\circ}$ on the sample deformed up to $35 \%$ of plastic strain. Figure 4 presents this gradual decline clearly, where water droplets spread more on the surface in parallel with plastic deformation. These results are plotted against
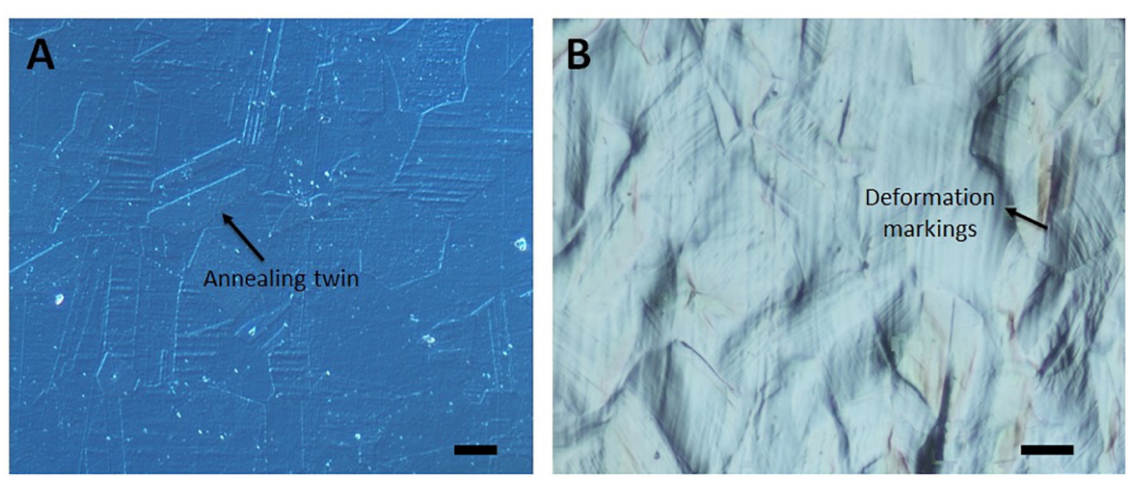

FIGURE 1 | Optical microscope DIC images of the (A) undeformed and (B) $25 \%$ deformed sample. Scale bars are $10 \mu \mathrm{m}$. (Figure is more readable and visible on the screen rather than in print).
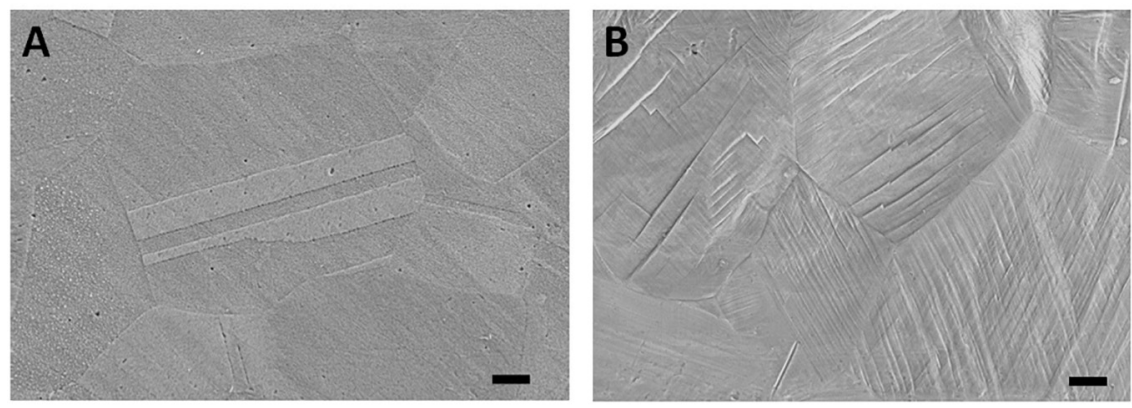

FIGURE 2 | Scanning electron microscopy images of the (A) undeformed and (B) $25 \%$ deformed samples. Scale bars are $3 \mu \mathrm{m}$. (Figure is more readable and visible on the screen rather than in print). 

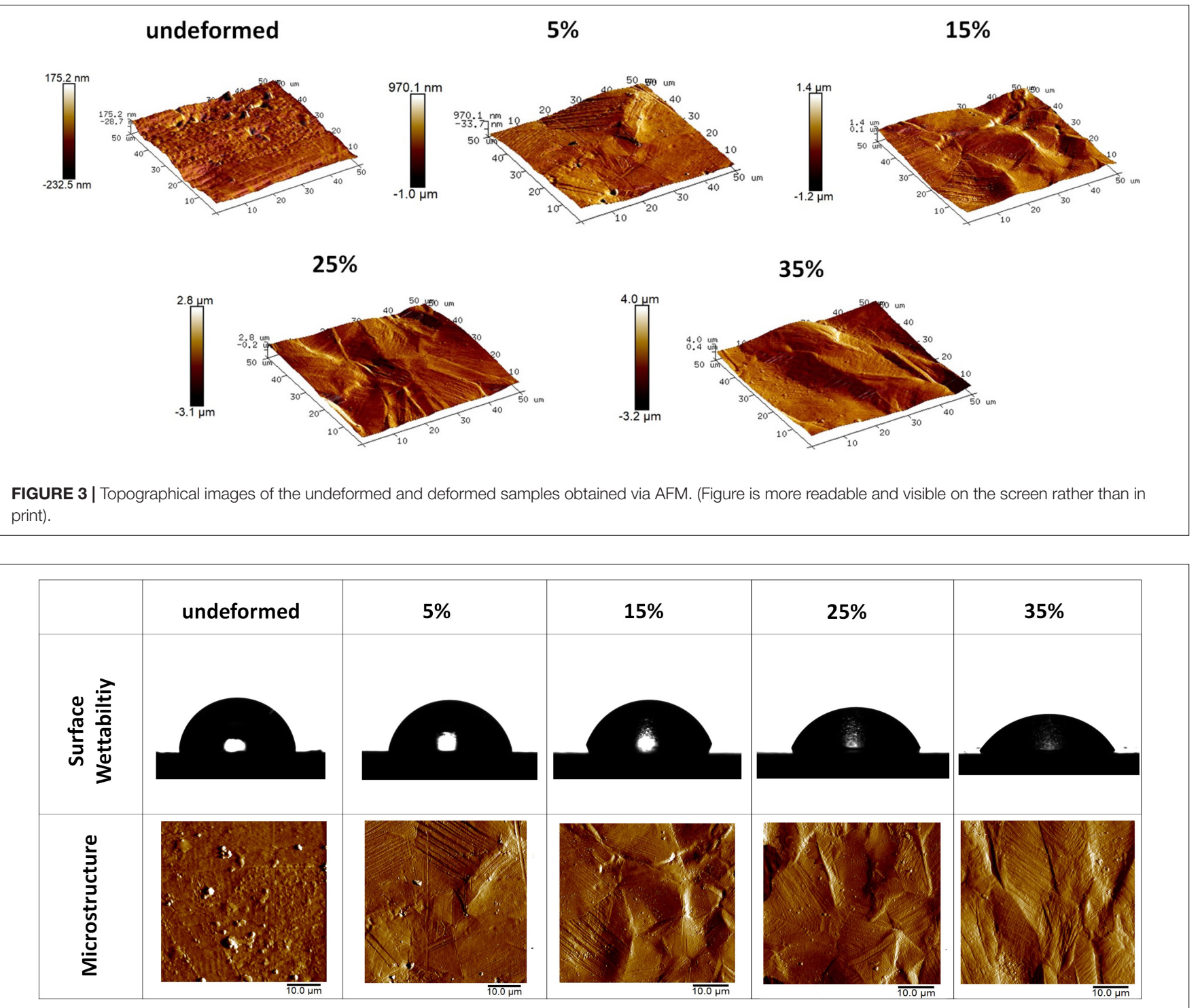

FIGURE 4 | Photographs of the water droplets on the undeformed and deformed samples represent the wettability of the samples. AFM amplitude images of the undeformed and deformed samples show the influence of plastic deformation on the microstructure. (Figure is more readable and visible on the screen rather than in print).

TABLE 1 | Water contact angle, surface free energy, average surface roughness, and number of attached cells values of the undeformed and deformed samples.

\begin{tabular}{|c|c|c|c|c|c|}
\hline & Undeformed & $5 \%$ & $15 \%$ & $25 \%$ & $35 \%$ \\
\hline Surface free energy $\left(\mathrm{mJ} / \mathrm{m}^{2}\right)$ & $36.06 \pm 0.82$ & $38.14 \pm 0.19$ & $42.45 \pm 0.18$ & $45.37 \pm 0.23$ & $48.89 \pm 0.75$ \\
\hline No. of attached cells & $232.78 \pm 3.78$ & - & - & - & $557 \pm 90.67$ \\
\hline
\end{tabular}

plastic strain in order to clearly present the relative changes measured in surface roughness and water contact angle values (Figure 5). One-way ANOVA results of the surface wettability data indicate that all group means are not equal $\left[F_{(4,10)}=58.49\right.$, $p<0.001]$. Additional post hoc multiple comparisons (LSD) indicate that all group means are significantly different from each other at $p<0.05$ level or better. These results are also confirmed by non-parametric Kruskal-Wallis tests $\left[\chi^{2}{ }_{(4)}=13.5 ; p<0.01\right]$.

Next, presented in Table $\mathbf{1}$ are the results of the SFE analyses. As can be observed in this table, surface energy increases from $36.06 \pm 0.82$ to $48.89 \pm 0.75 \mathrm{~mJ} / \mathrm{m}^{2}$ as the applied plastic strain reaches up to $35 \%$ from the non-deformed state, and the 


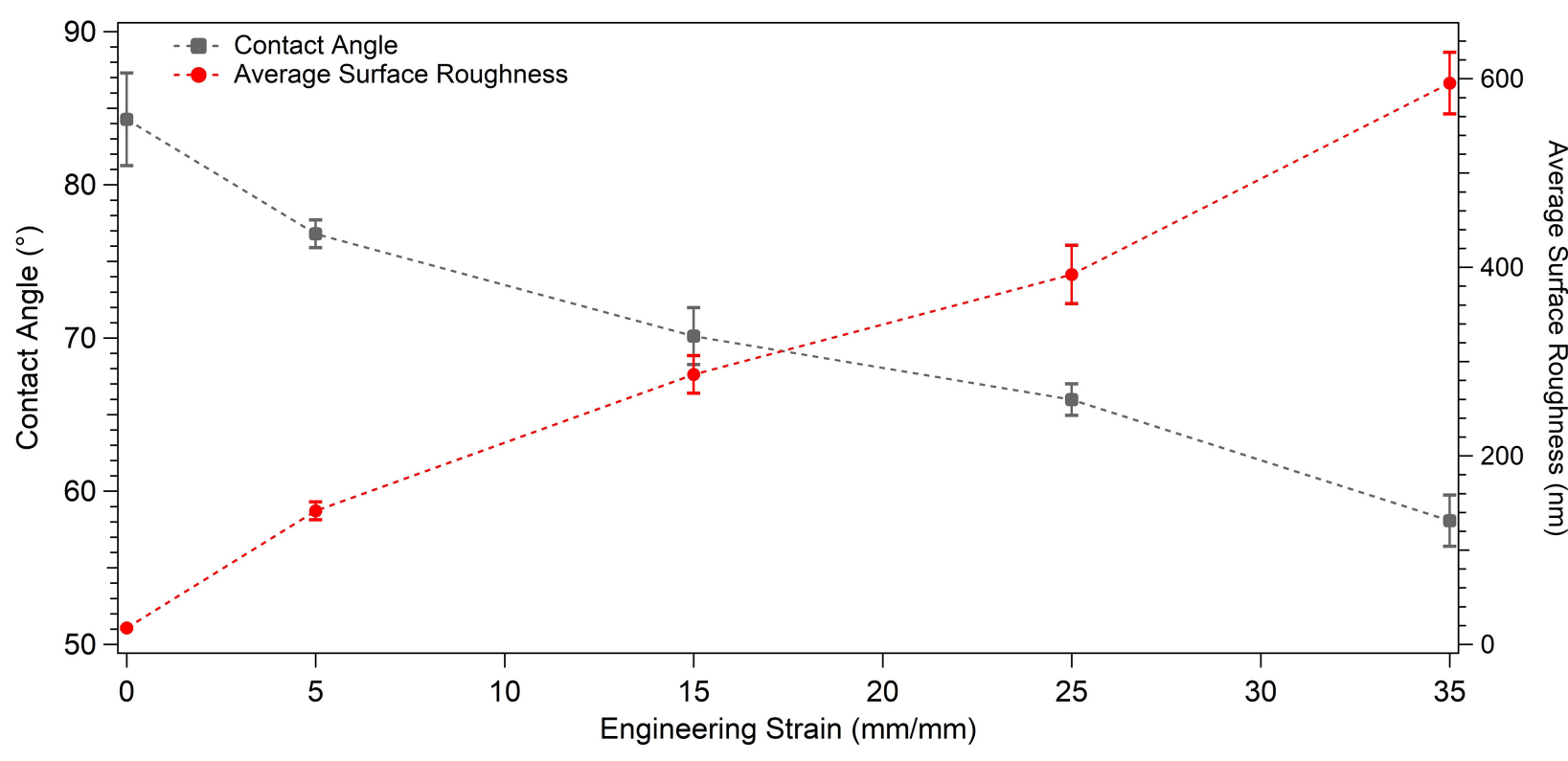

FIGURE 5 | Graph presenting the water contact angle and average surface roughness values of the undeformed and plastically deformed samples.

observed difference is statistically significant $(p<0.001)$. More specifically, the null hypothesis stating that all five group means are equal is rejected $\left[F_{(4,10)}=199.8, p<0.001\right]$, and post hoc multiple comparisons (LSD) indicate that each group mean is significantly different from others at $p<0.05$ level or better. These results are also confirmed by non-parametric KruskalWallis tests $\left[\chi^{2}(4)=13.5 ; p<0.01\right]$.

The adhesion and spreading behavior of the cells were closely monitored with SEM. Figures 6, 7 present similar cell morphology and attachment behaviors on the undeformed and $35 \%$ deformed samples. Cytoplasmic protrusions, such as filopodia or lamellipodia, can be observed on both of these samples.

Breast cancer cells with DAPI-labeled nuclei on the undeformed and 35\% deformed samples were also monitored via confocal microscope (Figure 8). The quantified data of the attached cells are presented in Table 1. These results show that the cell attachment increases on average 2.4-fold on the 35\% deformed sample compared to the control sample. Furthermore, a non-parametric Mann-Whitney $U$ test indicates that the difference in number of cell attachments on these two samples is statistically significant $(p<0.001)$.

\section{DISCUSSION}

The significant microstructural differences observed between the undeformed and deformed samples via optical microscopy and SEM techniques stem from the introduction of surface relief via activated plastic deformation mechanisms in different volume fractions. Slip, mechanical twinning, or martensite can get activated on $304 \mathrm{~L}$ stainless-steel samples, contributing to hardening and ductility of the material (Hamdi and Asgari,
2008; Shen et al., 2012). The hierarchical structures of these mechanisms can be observed in Figure 2B, where they interact with each other and further contribute to strengthening of the material (Uzer et al., 2016). Moreover, elongated grains observed on the $35 \%$ deformed sample can show tensile plasticity of the steel sample (Qu et al., 2008), which constitutes importance in defining the plastic deformation capability of the bulk material.

Increasing volume fraction of the strengthening mechanisms within the bulk material is represented with a more distorted surface, as indicated in the literature (Sinha et al., 2015). The reflection of these mechanisms on the material surface, namely, surface relief, can be observed in the SEM and AFM observations. Specifically, it is clearly seen in Figures 3, 4 that the deformation markings protruding out of the material surface modify surface topography significantly and increase surface roughness (Matsugaki et al., 2012; Matsugaki and Nakano, 2016; Uzer et al., 2016). Misorientation angle between the neighboring grains might increase with plastic straining further contributing to the roughness of the samples (Sinha et al., 2015; Srinivasan et al., 2016). $R_{\mathrm{a}}$ of the $35 \%$ deformed sample showed approximately 34 -fold increase compared to the undeformed sample (Table 1). It is important to note that this increase on the polycrystalline stainless steels was related earlier specifically with the activation of deformation twinning, which causes abrupt changes on the texture (Uzer et al., 2016). Hence, designing the material microstructure, which would preferably activate twinning upon deformation, could be advantageous to achieve microscale surface topography and advanced tissueimplant integration.

The water contact angle results show that the $35 \%$ deformed sample presents the highest hydrophilicity. This increase in the wettability behavior can be stemming from the increased surface roughness due to surface relief and high-energy regions provided 

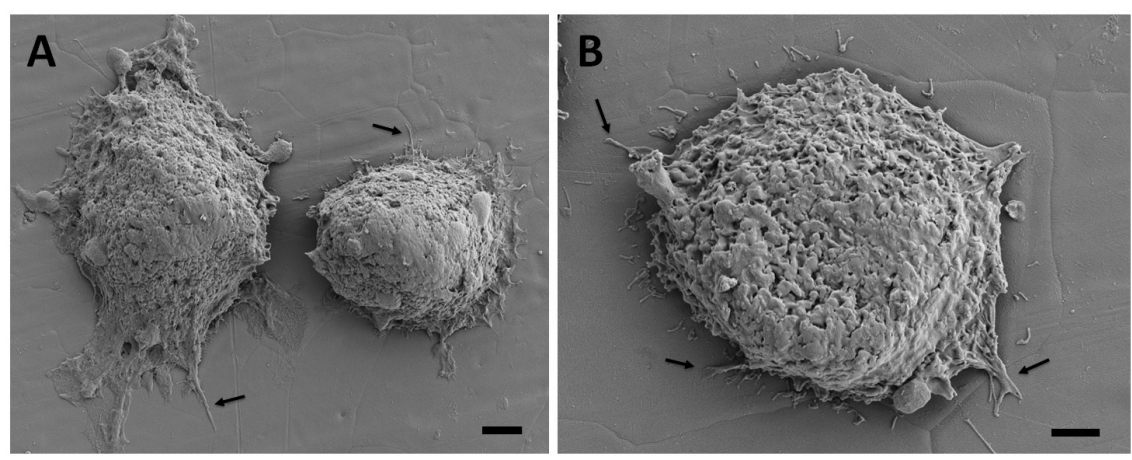

FIGURE 6 | Scanning electron microscopy images of the breast cancer cells attached on the undeformed stainless-steel samples. Figure in (A) shows two neighboring cells and (B) shows a single cell with higher magnification. Arrows point out the cytoplasmic protrusions. Scale bars are 3 and $2 \mu \mathrm{m}$, respectively.
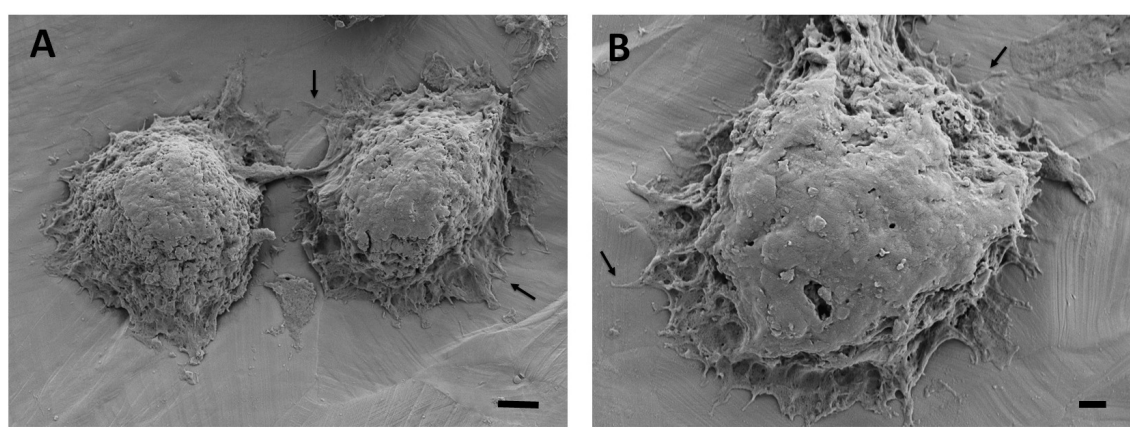

FIGURE 7 | Scanning electron microscopy images of the breast cancer cells attached on the 35\% deformed stainless-steel samples. Figure in (A) shows two neighboring cells and (B) shows a single cell with higher magnification. Arrows point out the cytoplasmic protrusions. Scale bars are 3 and $1 \mu \mathrm{m}$, respectively.
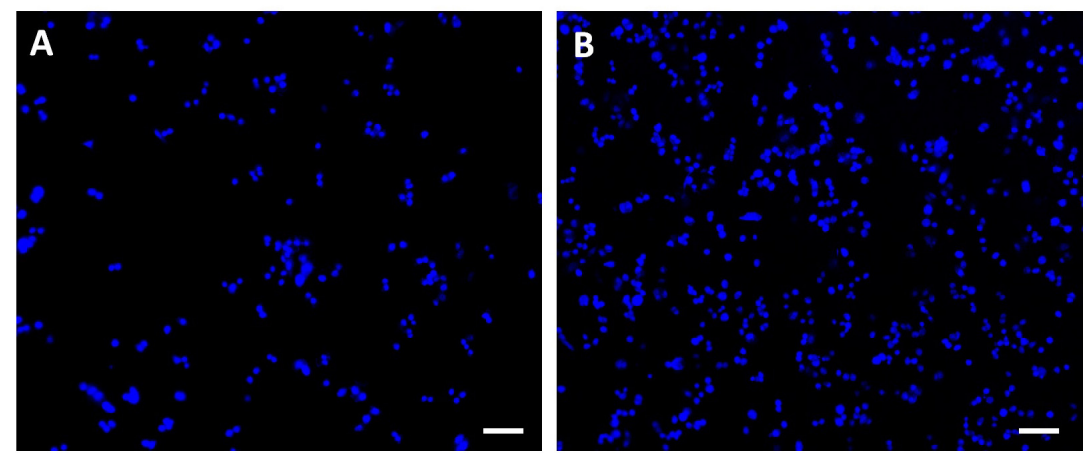

FIGURE 8 | Confocal microscope images of the breast cancer cells with DAPI-labeled nuclei attached on the (A) undeformed and (B) 35\% deformed sample. Scale bars are $100 \mu \mathrm{m}$.

by the activated strengthening mechanisms. It is noteworthy that surface wettability along with surface roughness may play pivotal role in the early tissue-implant integration (Rupp et al., 2014). That is, surfaces with enhanced wettability and roughness promote the deposition and spreading of cellular adhesion proteins on the implant surface via increasing surface exposure of biological molecules (Venkatsurya et al., 2012). This eventually could lead to improved tissue-implant integration within a shorter period of time (Venkatsurya et al., 2012; Uzer et al., 2016).
Hence, increased surface hydrophilicity as a result of bulk plastic deformation and surface relief can be effective for achieving a successful implantation.

The observed increase of surface wettability in parallel with surface roughness can be explained further with Wenzel's equation $\left(\cos \theta_{w}=r \cdot \cos \theta_{\text {young; }}\right.$; where $r, \theta_{w}$, and $\theta_{\text {young }}$ are roughness factor, apparent Wenzel contact angle, and Young contact angle, respectively) (Rupp et al., 2014; Cicek et al., 2019). Considering the $\theta_{w}$ of $58.07^{\circ}$, and $\theta_{\text {young }}$ of $84.28^{\circ}$, 
$r$ can be predicted as 5.3, which is the ratio between the actual and projected surface area. On the hydrophilic surfaces $\left(\theta_{\text {young }}<90^{\circ}\right)$, Wenzel equation suggests that surface wettability increases with higher levels of surface roughness. The greater hydrophilicity observed on the $35 \%$ deformed sample thus conforms well with Wenzel's theory.

Moreover, wetting is favored on the high-energy solid surfaces (Rupp et al., 2014), and therefore SFE of the material can also play significant role in tissue-implant integration (Rupp et al., 2014; Uzer et al., 2016). For instance, enhanced protein absorption, attachment, and differentiation of osteoblasts have been related with higher SFE of metallic implants (Miyajima et al., 2019). The SFE values calculated based on OW method in the current study increased gradually with plastic straining (Table 1). This result could be attributed to the activated strengthening mechanisms, which have created high-energy regions (Toker et al., 2014; Uzer et al., 2016; Nune et al., 2018). The interaction of slip, twinning, and martensite mechanisms can further increase these energetic regions, which can facilitate the adhesion of biological molecules on the surface (Toker et al., 2014). The role of metallic biomaterial's microstructure on cell response has been analyzed earlier, and enhanced cell adhesion was reported on the smaller grain sized sample, possibly due to increased grain boundary area and SFE (Choubey et al., 2009; Misra et al., 2013). In the current study, the energy-rich twin boundaries, which increase in total area parallel with plastic straining, can also contribute to increased levels of SFE concomitant with the preexisting grain boundaries.

Scanning electron microscopy analyses of the breast cancer cells attached on the undeformed and 35\% deformed samples show similar morphologies. Specifically, cytoplasmic protrusions (i.e., lamellipodia or filopodia), which play a crucial role in cancer cell invasion and metastasis (Caswell and Zech, 2018), were formed on both of these samples (Figures 6, 7). These integrinrich protrusions can regulate cell adhesion, because they are involved in the formation of focal contact points (Caswell and Zech, 2018). Next, the observed 2.4-fold increase in the number of breast cancer cell attachment on the 35\% deformed sample compared to the undeformed sample (Figure 8) indicates that the aforementioned improved surface properties have provided an advantageous environment for cancer cells. Specifically, increased SFE and wettability on the 35\% deformed sample (the highest level of surface relief) would have promoted the deposition of the adhesion proteins, enhancing the attachment of a greater number of cells. Overall, these results indicate that enhanced surface properties via surface relief may increase the number of cell attachments on the implant surface, but may not be influential in the morphology or spreading behavior of the breast cancer cells. Further investigations would be needed to understand mechanisms governing the greater number of cell attachment on the deformed surfaces.

It is well known that the initial interaction of healthy cells (e.g., osteoblasts or fibroblasts) with implant surfaces constitutes significance for establishing successful tissue-implant integration (Nune et al., 2018; Uzer et al., 2018; Raines et al., 2019). When it comes to cancer cells, however, enhanced attachment on the biomaterial surface could be utilized for therapeutic purposes, where cells could be captured on the material before metastasizing to other tissues (Azarin et al., 2015). Azarin et al. (2015) have shown a decrease in tumor burden by developing a polymer implant, which has been used to capture and detect metastasizing breast cancer cells before reaching another organ. In that way, the metastatic disease has been identified at an early stage, and the progression of the disease has been halted. Findings from the current study could also pave the way for a new stream of research revealing potential applications of metallic biomaterials for a similar purpose, whereby cancer cells' attachment would be regulated via modulated surface properties and the progression of the disease could be slowed.

Improvement of the surface properties and cell response was also achieved by surface plastic deformation methods, such as sandblasting, shot peening, or sliding friction earlier (Frutos et al., 2010; Bagherifard et al., 2016; Huo et al., 2017). Arifvianto et al. (2011) have investigated the wettability of the SMAT applied 316L stainless steels, which showed decrease in the contact angle from 88.6 to $74.4^{\circ}$, while surface roughness of the deformed sample increased up to a range of 681 to $909 \mathrm{~nm}$, which is greater than the $R_{\mathrm{a}}$ attained in the current study. Greater hydrophilicity obtained in the current study could be stemming from the activation of deformation mechanisms throughout the bulk material (in comparison to activation in Arifvianto et al. (2011) study predominantly on the material surface). Specifically, surface plastic deformation methods can cause early saturation of the activation of slip, twinning, or martensite, because plastic deformation takes place within the limited deformation zone (Arifvianto et al., 2011). However, bulk plastic deformation can lead to the activation of the strengthening mechanisms in greater densities throughout the bulk material, which can increase highenergy regions more significantly.

This finding is consistent with those in prior studies, where the materials have been subjected to bulk plastic deformation methods, for example, rolling or equal angular channel pressing (ECAP) processes (Misra et al., 2013; Günay-Bulutsuz et al., 2018). Specifically, as the grains of the pure titanium samples were refined through the ECAP process, contact angle decrease from $82.56^{\circ}$ down to $41.28^{\circ}$ was captured on the postmortem polished surface (Günay-Bulutsuz et al., 2018). This can imply that bulk plastic deformation methods can effectively increase hydrophilicity of materials. Hence, bulk plasticity could play a crucial role in determining surface characteristics of the material. However, it is important to note that surface wettability and energy can also be influenced strongly by surface chemistry (Latifi et al., 2013). Therefore, in order to thoroughly elucidate the role of plastic deformation on surface properties and cell response, further systematic analyses need to be carried out.

\section{CONCLUSION}

In this study, surface properties regulating cell-implant interactions have been investigated on the plastically deformed 304L stainless-steel samples. The tensile loading of the samples up to $5,15,25 \%$ and $35 \%$ of plastic strains has resulted with surface relief in different volume fractions. The greatest surface 
wettability $\left(\theta_{w}=58.07^{\circ} \pm 1.67^{\circ}\right)$, SFE $\left(48.89 \pm 0.75 \mathrm{~mJ} / \mathrm{m}^{2}\right)$, and roughness $\left(R_{\mathrm{a}}=595.29 \pm 32.74 \mathrm{~nm}\right)$ were attained on the $35 \%$ deformed sample. Furthermore breast cancer cells presented an approximately 2.4-fold increased number of cell attachment on the $35 \%$ deformed sample compared to the undeformed control one. Whereas cell morphology and spreading showed similarity on these two samples. The following markings have been concluded:

1. Increasing volume fraction of the twinning, slip, and martensite activated on the samples via bulk plastic deformation technique can be an effective way to impart $\mathrm{micro} /$ nanoscale texture and modulate surface properties.

2. Increased SFE could be stemming from the high-energy regions created with strengthening mechanisms and increased surface area of the energy-rich boundaries (twin and grain).

3. Relatively higher number of cells attached on the $35 \%$ deformed sample can indicate that implants with surfaces modulated by plastic deformation processes can be utilized for therapeutic purposes via capturing metastatic cancers and slowing the progression of disease.

4. Bulk and surface plastic deformation techniques can each result with different surface properties, which could influence cell response accordingly.

Overall, the aforementioned listed findings provide insight on how surface relief can influence surface properties of the implants

\section{REFERENCES}

Arifvianto, B., Suyitno, M., Mahardika, M., Dewo, P., Iswanto, P. T., and Salim, U. A. (2011). Effect of surface mechanical attrition treatment (SMAT) on microhardness, surface roughness and wettability of AISI 316L. Mater. Chem. Phys. 125, 418-426. doi: 10.1016/j.matchemphys.2010.10.038

Azarin, S. M., Yi, J., Gower, R. M., Aguado, B. A., Sullivan, M. E., Goodman, A. G., et al. (2015). In vivo capture and label-free detection of early metastatic cells. Nat. Commun. 6, 1-9. doi: 10.1038/ncomms9094

Bagherifard, S., Slawik, S., Fernández-pariente, I., Pauly, C., Mücklich, F., and Guagliano, M. (2016). Nanoscale surface modification of AISI 316L stainless steel by severe shot peening. Mater. Design 102, 68-77. doi: 10.1016/j.matdes. 2016.03.162

Barthes, J., Özçelik, H., Hindie, M., Ndreu-Halili, A., Anwarul, H., and Vrana, N. E. (2014). Cell Microenvironment engineering and monitoring for tissue engineering and regenerative medicine: the citation accessed citable link cell microenvironment engineering and monitoring for tissue engineering and regenerative medicine: the recent advances. Biomed. Res. Intern. 2014, 1-18. doi: $10.1155 / 2014 / 921905$

Bauer, S., Schmuki, P., von der Mark, K., and Park, J. (2013). Engineering biocompatible implant surfaces. Prog. Mater. Sci. 58, 261-326. doi: 10.1016/j. pmatsci.2012.09.001

Beri, P., Matte, B. F., Fattet, L., Kim, D., Yang, J., and Engler, A. J. (2018). Biomaterials to model and measure epithelial cancers. Nat. Rev. Mater. 3, 418-430. doi: 10.1038/s41578-018-0051-6

Caswell, P. T. and Zech, T. (2018). Actin-based cell protrusion in a $3 \mathrm{D}$ matrix. Trends Cell Biol. 28, 823-834. doi: 10.1016/j.tcb.2018.06.003

Chen, Q., and Thouas, G. (2015). Metallic implant biomaterials. Mater. Sci. Eng. R Rep. 87, 1-57. doi: 10.1016/j.mser.2014.10.001

Chen, W., Allen, S. G., Reka, A. K., Qian, W., Han, S., Zhao, J., et al. (2016). Nanoroughened adhesion-based capture of circulating tumor cells with heterogeneous expression and metastatic characteristics. BMC Cancer 16:614. doi: $10.1186 / \mathrm{s} 12885-016-2638-\mathrm{x}$ and attachment behavior of the breast cancer cells. These results could be utilized in the design of implants for therapeutic or diagnostic purposes. Further investigations would be needed to understand mechanisms governing the cancer cell adhesion on the metallic implants.

\section{DATA AVAILABILITY STATEMENT}

All datasets generated for this study are included in the article/supplementary material.

\section{AUTHOR CONTRIBUTIONS}

The author confirms being the sole contributor of this work and has approved it for publication.

\section{ACKNOWLEDGMENTS}

The author would like to thank Şeyma Dad $\iota$ for contact angle measurements, Nazende Nur Akşit for cell culture experiments and İhsan Aksit for AFM analyses. The author also acknowledges Dr. M. Serdar Onses for his valuable comments.

Choubey, A., Marton, D., and Sprague, E. A. (2009). Human aortic endothelial cell response to $316 \mathrm{~L}$ stainless steel material microstructure. J. Mater. Sci. Mater. Med. 20, 2105-2116. doi: 10.1007/s10856-009-3780-7

Cicek, S., Karaca, A., Torun, I., Onses, M. S., and Uzer, B. (2019). The relationship of surface roughness and wettability of $316 \mathrm{~L}$ stainless steel implants with plastic deformation mechanisms. Mater. Today Proc. 7, 389-393. doi: 10.1016/j.matpr. 2018.11.100

Conde, J., Shomron, N., and Artzi, N. (2016). Biomaterials for metastasis: bridging the gap between basic and translational research. Adv. Healthc. Mater. 5, 2312-2319. doi: 10.1002/adhm.201600414

Frutos, E., Multigner, M., and González-Carrasco, J. L. (2010). Novel approaches to determining residual stresses by ultramicroindentation techniques: application to sandblasted austenitic stainless steel. Acta Mater. 58, 4191-4198.

Gentile, F., Tirinato, L., Battista, E., Causa, F., Liberale, C., di Fabrizio, E. M., et al. (2010). Biomaterials cells preferentially grow on rough substrates. Biomaterials 31, 7205-7212. doi: 10.1016/j.biomaterials.2010.06.016

Gui, N., Xu, W., Tian, J., Rosengarten, G., Brandt, M., and Qian, M. (2018). Fabrication and anisotropic wettability of titanium-coated microgrooves. J. Appl. Phys. 123:95306. doi: 10.1063/1.5020517

Günay-Bulutsuz, A., Berrak, O., Aygül Yeprem, H., and Arisan, E. D. (2018). Materials science \& engineering $\mathrm{C}$ biological responses of ultra Fi Ne grained pure titanium and their sand blasted surfaces. Mater. Sci. Eng. C 91, 382-388. doi: 10.1016/j.msec.2018.05.056

Hamdi, F., and Asgari, S. (2008). Evaluation of the role of deformation twinning in work hardening behavior of face-centered-cubic polycrystals. Metallurg. Mater. Trans. A 39, 294-303. doi: 10.1007/s11661-007-9356-6

Hanawa, T. (2019). Titanium - tissue interface reaction and its control with surface treatment. Front. Bioeng. Biotechnol. 7:170. doi: 10.3389/fbioe.2019. 00170

Huo, W. T., Zhao, L. Z., Yu, S., Yu, Z. T., Zhang, P. X., and Zhang, Y. S. (2017). Significantly enhanced osteoblast response to nano-grained pure tantalum. Sci. Rep. 7, 1-13. doi: 10.1038/srep40868 
Kunrath, M. F., and Hübler, R. (2019). A Bone preservation protocol that enables evaluation of osseointegration of implants with micro- and nanotextured surfaces. Biotech. Histochem. 94, 261-270. doi: 10.1080/10520295.2018.1552017

Latifi, A., Imani, M., Khorasani, M. T., and Joupari, M. D. (2013). Electrochemical and chemical methods for improving surface characteristics of $316 \mathrm{~L}$ stainless steel for biomedical applications. Surf. Coat. Technol. 221, 1-12. doi: 10.1016/j. surfcoat.2013.01.020

Le Guéhennec, L., Soueidan, A., Layrolle, P., and Amouriq, Y. (2007). Surface treatments of titanium dental implants for rapid osseointegration. Dent. Mater. 23, 844-854. doi: 10.1016/j.dental.2006.06.025

Liu, K., and Jiang, L. (2011). Metallic surfaces with special wettability. Nanoscale 3, 825-838.

Matsugaki, A., Aramoto, G., and Nakano, T. (2012). The alignment of MC3T3E1 osteoblasts on steps of slip traces introduced by dislocation motion. Biomaterials 33, 7327-7335. doi: 10.1016/j.biomaterials.2012.06.022

Matsugaki, A., and Nakano, T. (2016). Control of cellular arrangement by surface topography induced by plastic deformation. Crystals 6:73. doi: 10.3390/ cryst 6060073

Misra, R. D. K., Nune, K. C., Pesacreta, T. C., Somani, M. C., and Karjalainen, L. P. (2013). Understanding the impact of grain structure in austenitic stainless steel from a nanograined regime to a coarse-grained regime on osteoblast functions using a novel metal deformation-annealing sequence. Acta Biomater. 9, 6245-6258. doi: 10.1016/j.actbio.2012.12.003

Misra, R. D. K., Thein-Han, W. W., Pesacreta, T. C., Hasenstein, K. H., Somani, M. C., and Karjalainen, L. P. (2009). Cellular response of preosteoblasts to nanograined/ultrafine-grained structures. Acta Biomater. 5, 1455-1467. doi: 10.1016/j.actbio.2008.12.017

Miyajima, H., Awadzi, G., Ozer, F., and Mante, F. K. (2019). Effect of surface physico-chemico-biological modification of titanium on critical and theoretical surface free energy. Appl. Surf. Sci. 470, 386-394. doi: 10.1016/j.apsusc.2018.11. 133

Multigner, M., Ferreira-Barragáns, S., Frutos, E., Jaafar, M., Ibáñez, J., Marín, P., et al. (2010). Surface \& coatings technology superficial severe plastic deformation of 316 LVM stainless steel through grit blasting: effects on its microstructure and subsurface mechanical properties. Surf. Coat. Technol. 205, 1830-1837. doi: 10.1016/j.surfcoat.2010.07.126

Nune, K. C., Montes, I., Injeti, V. S. Y., Somani, M. C., and Misra, R. D. K. (2018). The determining role of nanoscale mechanical twinning on cellular functions of nanostructured materials. J. Mech. Behav. Biomed. Mater. 88, 185-195. doi: 10.1016/j.jmbbm.2018.08.033

Peron, M., Torgersen, J., and Berto, F. (2017). Mg and its alloys for biomedical applications: exploring corrosion and its interplay with mechanical failure. Metals 252, 1-41. doi: 10.3390/met7070252

Ponsonnet, L., Reybier, K., Jaffrezic, N., Comte, V., Lagneau, C., Lissac, M., et al. (2003). Relationship between surface properties (roughness, wettability) of titanium and titanium alloys and cell behaviour. Mater. Sci. Eng. C 23, 551-560. doi: 10.1016/S0928-4931(03)00033-X

Qu, S., Huang, C. X., Gao, Y. L., Yang, G., Wu, S. D., Zang, Q. S., et al. (2008). Tensile and compressive properties of AISI 304L stainless steel subjected to equal channel angular pressing. Mater. Sci. Eng. A 475, 207-216. doi: 10.1016/j. msea.2007.04.111

Raines, A. L., Berger, M. B., Schwartz, Z., and Boyan, B. D. (2019). Osteoblasts grown on microroughened titanium surfaces regulate angiogenic growth factor production through specific integrin receptors. Acta Biomater. 97, 578-586. doi: 10.1016/j.actbio.2019.07.036

Ranella, A., Barberoglou, M., Bakogianni, S., Fotakis, C., and Stratakis, E. (2010). Tuning cell adhesion by controlling the roughness and wettability of 3D Micro/Nano Silicon structures. Acta Biomater. 6, 2711-2720. doi: 10.1016/j. actbio.2010.01.016

Ray, A., Slama, Z. M., Morford, R. K., Madden, S. A., and Provenzano, P. P. (2017). Enhanced directional migration of cancer stem cells in $3 \mathrm{D}$ aligned collagen matrices. Biophys. J. 112, 1023-1036. doi: 10.1016/j.bpj.2017.01.007
Rupp, F., Gittens, R. A., Scheideler, L., Marmur, A., Boyan, B. D., Schwartz, Z., et al. (2014). A review on the wettability of dental implant surfaces i: theoretical and experimental aspects. Acta Biomater. 10, 2894-2906. doi: 10.1016/j.actbio.2014. 02.040

Shen, Y. F., Li, X. X., Sun, X., Wang, Y. D., and Zuo, L. (2012). Twinning and martensite in a 304 austenitic stainless steel. Mater. Sci. Eng. A 552, 514-522. doi: 10.1016/j.msea.2012.05.080

Sinha, S., Szpunar, J. A., Kiran Kumar, N. A. P., and Gurao, N. P. (2015). Tensile deformation of $316 \mathrm{~L}$ austenitic stainless steel using in-situ electron backscatter diffraction and crystal plasticity simulations. Mater. Sci. Eng. A 637, 48-55. doi: 10.1016/j.msea.2015.04.005

Srinivasan, N., Kain, V., Birbilis, N., Sunil Kumar, B., Gandhi, M. N., Sivaprasad, P. V., et al. (2016). Plastic deformation and corrosion in austenitic stainless steel: a novel approach through microtexture and infrared spectroscopy. Eval. Program Plan. 111, 404-413. doi: 10.1016/j.corsci.2016. 05.027

Tabdanov, E. D., Puram, V. V., Win, Z., Alamgir, A., Alford, P. W., and Provenzano, P. P. (2018). Bimodal sensing of guidance cues in mechanically distinct microenvironments. Nat. Commun. 9, 1-18. doi: 10.1038/s41467-01807290-y

Toker, S. M., Canadinc, D., Maier, H. J., and Birer, O. (2014). Evaluation of passive oxide layer formation-biocompatibility relationship in NiTi shape memory alloys: geometry and body location dependency. Mater. Sci. Eng. C 36, 118-129. doi: 10.1016/j.msec.2013.11.040

Uzer, B., and Canadinc, D. (2018). The effect of plastic deformation on the cell viability and adhesion behavior in metallic implant materials. Process. Prop. Design Adv. Ceram. Composi. II Ceram. Trans. 261, 187-196. doi: 10.1002/ 9781119423829.ch16

Uzer, B., Monte, F., Kamal, R. A., Aswath, P. B., Varanasi, V. G., and Canadinc, D. (2018). The influence of plastic deformation mechanisms on the adhesion behavior and collagen formation in osteoblast cells. Miner. Metals Mater. Ser. Part F 12, 295-301. doi: 10.1007/978-3-319-725 26-0_27

Uzer, B., Toker, S. M., Cingoz, A., Bagci-Onder, T., Gerstein, G., Maier, H. J., et al. (2016). An exploration of plastic deformation dependence of cell viability and adhesion in metallic implant materials. J. Mech. Behav. Biomed. Mater. 60, 177-186. doi: 10.1016/j.jmbbm.2016.01.001

Valiev, R. Z., Estrin, Y., Horita, Z., Langdon, T. G., Zehetbauer, M. J., and Zhu, Y. (2016). Producing bulk ultrafine-grained materials by severe plastic deformation: ten years later. JOM 68, 1216-1226.

Venkatsurya, P. K. C., Girase, B., Misra, R. D. K., Pesacreta, T. C., Somani, M. C., and Karjalainen, L. P. (2012). The interplay between osteoblast functions and the degree of nanoscale roughness induced by grain boundary grooving of nanograined materials. Mater. Sci. Eng. C 32, 330-340. doi: 10.1016/j.msec. 2011.10.036

Ventre, M., Causa, F., and Netti, P. A. (2012). Determinants of cell - material crosstalk at the interface: towards engineering of cell instructive materials. J. $R$. Soc. Interf. 9, 2017-2032. doi: 10.1098/rsif.2012.0308

Weiss, S., and Mitevski, B. (2015). Microstructure and deformation of coronary stents from CoCr-Alloys with different designs. Materials 8, 2467-2479. doi: $10.3390 / \mathrm{ma} 8052467$

Conflict of Interest: The author declares that the research was conducted in the absence of any commercial or financial relationships that could be construed as a potential conflict of interest.

Copyright (C) 2020 Uzer. This is an open-access article distributed under the terms of the Creative Commons Attribution License (CC BY). The use, distribution or reproduction in other forums is permitted, provided the original author(s) and the copyright owner(s) are credited and that the original publication in this journal is cited, in accordance with accepted academic practice. No use, distribution or reproduction is permitted which does not comply with these terms. 